\title{
THE BEHAVIOUR OF RAILWAY LEVEL CROSSINGS: INSIGHTS THROUGH FIELD MONITORING.
}

Louis Le Pen ${ }^{1 *}$, PhD CEng MICE, Geoff Watson ${ }^{2^{*}}$, BSc \& William Powrie ${ }^{3^{*}}$, FREng MA MSC PhD CEng FICE

${ }^{1}$ Senior Research Fellow, email: Ilp@soton.ac.uk

${ }^{2}$ Research Fellow, email: g.watson@soton.ac.uk

${ }^{3}$ Professor and Dean, email: wp@soton.ac.uk

* University of Southampton, University Road, Highfield, Southampton, SO17 1BJ, United Kingdom

${\text { Graeme } \mathrm{Yeo}^{4 \dagger} \text {, Paul Weston }}^{5+}$ \& Clive Roberts $^{6+}$

${ }^{4}$ PhD candidate, email: gjy246@bham.ac.uk

${ }^{5}$ Research Fellow, email: p.weston@bham.ac.uk

${ }^{6}$ Professor, email: c.roberts.20@bham.ac.uk

${ }^{\dagger}$ University of Birmingham, Edgbaston, Birmingham, B15 2TT, United Kingdom

Key words: level crossing, ballast, railway, railroad, geophones, digital image correlation, transition

\section{Abstract}

The development of reliable methods for measuring deflections as trains pass has enabled valuable insights into railway track behaviour to be gained. This is especially useful for problem areas such as transitions from normal ground onto hard substructures and complex track geometries such as switches and crossings.

To date, much of the research on transition zone behaviour has focussed on transitions associated with underbridges and other substructures. Switches and crossings have received some attention and level crossings generally very little. This paper describes and discusses the behaviour of a transition onto a level crossing in the south of England, UK. Measurements are presented from both trackside and on-train instruments. It is found that at this crossing, maintenance constraints have resulted in a group of unsupported or hanging sleepers on the approach to the crossing; and that this fault is not effectively rectified by tamping. Comparisons are also made between the way the fault shows up in measurements from trains of the loaded track profile and data from trackside measurements.

\section{Introduction}

Transition zones occur at changes of track form and / or sub-base properties, and are characterised by a change in the effective track support stiffness seen by a train. Often, the track will transition onto a substructure or a different track form that is less susceptible to, or incapable of, settlement - for example, an underbridge or a concrete slab track. This 
sudden increase in support stiffness or resilient modulus gives rise to additional dynamic forces associated with a change in the vertical position of the wheel which, over a number of loading cycles, can lead to the development of differential permanent settlements, increased loads and an accelerated rate of track geometry deterioration. Similarly, a sudden decrease in the support stiffness gives rise to additional impact loads as wheels drop to accommodate the increased deflection caused by train passage. This recursive link between resilient modulus / subgrade strength, dynamic load, and settlement / geometry deterioration are well known; see, for example, the discussion by Li and Davis (2005) and finite element analyses by Banimahd et al. (2012).

A further concern is the ability to maintain the transition by conventional means. If the transition does not include a minimum continuous depth of ballast (usually at least $200 \mathrm{~mm}$ ) beneath the sleepers leading up to and over the changed track form, mechanized methods of track maintenance, such as tamping, are difficult to use right up to and over the change in track form. This could result in a group of sleepers that are never mechanically maintained becoming unsupported or hanging, reducing further the apparent support stiffness seen by the train and accelerating the rate of geometry deterioration. Even when a continuous minimum depth of ballast is provided, problems with hanging sleepers can arise if the feature being crossed is short and very stiff, as demonstrated by Coelho et al. (2011) for a piled reinforced concrete culvert passing underneath a railway in the Netherlands.

Most investigations into transition zone behaviour in the literature have been focused on the (perhaps more obvious) problems of transitions onto bridges or over culverts (e.g. Coelho et al., 2011, Tutumluer et al., 2012, and Paixao et al., 2013). A problem deserving just as much attention is that of transitions onto and off level crossings. Although level crossings do not experience as great a change in support structure stiffness as may be expected for structures such as bridges, there are particular difficulties in maintaining them so that the transition could be thought of as both due to changes in track structure (associated with providing a road surface) and discontinuities in maintenance practice. Moreover, there is a historical stock of level crossings (over 6500 in the UK) for which the construction form is not generally consistent and in some cases unknown.

The visible parts of the track at a level crossing are the rails and the concrete panels that form the road surface. Maintenance at such locations is problematic. In the UK, the relevant standard NR/L3/TRK/4041 (Network Rail, 2012) states that "level crossings are a fixed point in the profile of the track. The track shall not be lifted or re-canted through level crossings when track tamping is undertaken". Therefore, tampers are not permitted to lift the track near level crossings. This is significant because best practice tamping involves a design overlift of some tens of millimetres. This is needed to account for the fact that tamping disturbs the micromechanical structure of the ballast, so that when it is first reloaded newly tamped track will undergo large settlements as demonstrated in laboratory tests by Aingaran (2014). While the track may not be lifted through a level crossing it should still be possible to remove the crossing panels to tamp through and re-align the track.

However, there remain further significant practical difficulties to re-aligning the track. These include the limited scope to slew the track laterally without moving the crossing edge beams (with the consequent need for remedial works at the road surface interface) and also that 
tamping through crossings requires a road closure from the local authority which may have a lead time of 8-12 weeks. As a result, the level crossing panels are sometimes not removed and tamping operations are gradually ramped down over a distance of up to $20 \mathrm{~m}$ on either side of the crossing, leaving any geometry faults in place. Where tampers cannot be or are not deployed, handheld vibrating (Kango-type) hammers can be used to re-compact the ballast around and beneath individual sleepers but may not provide the same consistency of geometry realignment. Additionally, services and drainage running along the road may pass through specially constructed conduits or culverts beneath the track (as is the case for the level crossing studied here).

Thus the deviations from standard maintenance practice necessary at level crossings effectively create transition zones between conventionally-maintained ballasted track, and track that is partly stiffened by the presence of the concrete panels and tarmac roadway. Practical difficulties can also result in level crossings being left unmaintained for longer periods.

There are several ways in which the careful design of transitions onto hard structures such as bridges can prevent differential settlement, ensure that the support stiffness does not change abruptly, and mitigate the particular localised mechanisms of track degradation. If successful, these transitions should involve the same or less maintenance cost as regular track, and there is much current research into their effectiveness (e.g. Paixao et al., 2013; Li and Davis, 2005; Coelho et al. ,2011; Tutumluer et al., 2012). In contrast, there are no recognised transition designs for approaches to level crossings.

The potential problems caused by the lack of an effective transition design and ongoing maintenance restrictions at level crossings could be ameliorated by alternative designs and / or maintenance practices. One possible measure could be use of self levelling sleepers, that automatically increase in height to mitigate the effects of differential settlement (Muramoto et al., 2013). Such systems are not currently approved for use on the UK rail network, but their use could be justified if there were confidence that the additional initial costs would be more than offset by a reduction in future maintenance costs.

This paper aims to

- characterise the behaviour of the approach to a typical level crossing and

- assess the factors affecting the performance of the crossing over time, with reference to:

- trackside measurements of sleeper deflections during train passage, made using geophones and remote video monitoring and

- on-train measurements made from the track recording car and using an inertial measurement system mounted on a bogie of an in-service train.

The difficulties of obtaining spatial consistency between trackside and on-train measurement data are also discussed 


\section{Study site}

As part of a programme of on-going monitoring at problem sites in the UK (Track 21, 2014), the National Infrastructure Laboratory at the University of Southampton has been investigating track performance on the approach to a level crossing near a station in southern England, UK. The purpose of the investigation was initially to evaluate the before and after performance of a level crossing where a renewal was due to take place. However in the event, the renewal was only carried out on one side of the level crossing and did not extend over the zone selected for monitoring. The curtailment of the renewal further illustrates the difficulties of carrying out works through crossings. Nevertheless, the data available and the implementation of the one sided renewal have permitted an evaluation of the performance of the approach to the crossing over time and the effectiveness of a maintenance tamp that took place within the study period.

The study site is shown in Figure 1 . The site is underlain by soils of the London Clay formation (clay, silt and sand). Throughout this paper, distances are given from the edge of the level crossing on the side where measurements were carried out. At this location there are two tracks and the side of the track monitored is on the nearside of Figure 1 with trains moving from right to left. The start of a platform at a nearby station is about $200 \mathrm{~m}$ beyond the end of the level crossing, in the direction of train travel. A renewal took place through the station on 24 October 2012 but although this renewal was originally intended to include the crossing it was curtailed $35 \mathrm{~m}$ before the crossing, on the opposite side of the crossing to the monitoring location.

In addition to replacing the rails and the sleepers, renewal involved a formation treatment consisting of $250 \mathrm{~mm}$ depth of ballast to the current specification (Network Rail 2009), 50 $\mathrm{mm}$ of sand blanket and geocomposite (type PW4LA consisting of a geogrid and separator as described by the manufacturer: Fiberweb Geosynthetics Ltd., 2014).

Figure 2 shows the track bed being excavated in preparation for the renewal. The renewal permitted an assessment of the likely trackform below the study site (where there was no renewal). Figure 2 shows that the ballast is partly fouled and a brown sandy / silty / clayey formation, probably intermixed with ballast fragments has started to be exposed. Neither a geotextile nor a sandblanket are present.

A culvert passes below the track on the side of the level crossing studied; the inside of the top of the culvert was estimated to be at $0.7 \mathrm{~m}$ below sleeper level and is shown in Figure 4 . The culvert represents a potential hard spot beneath some of the sleepers near to the crossing. 


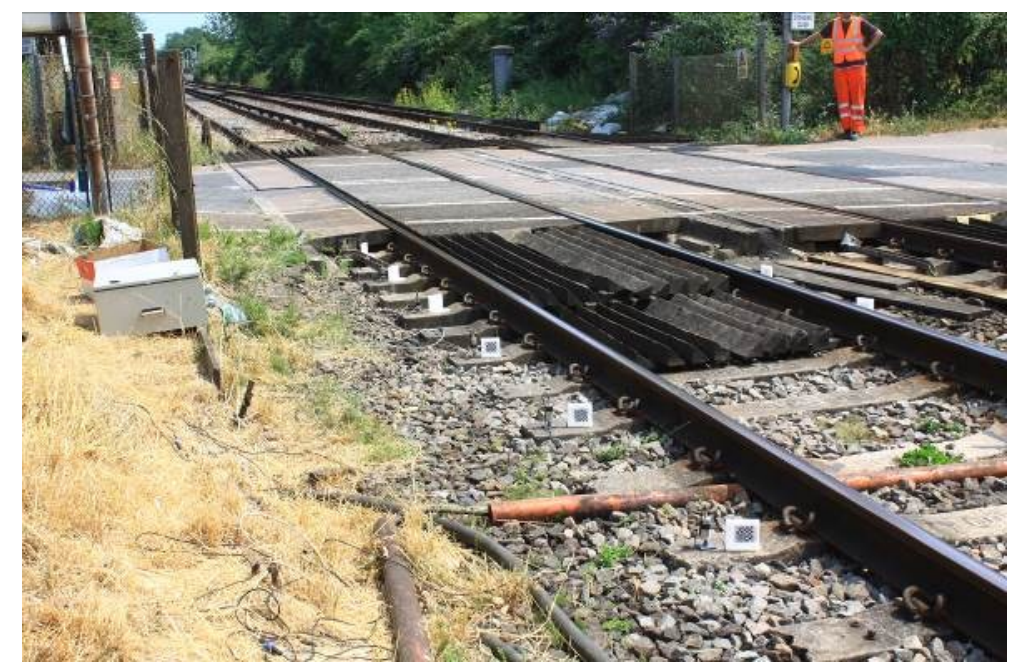

Figure 1: Photo of level crossing looking towards the nearby station in the direction of the train movement on the near track

The level crossing is surfaced with Bowmac concrete panels, visible in Figure 1 (and also in Figure 5, see later). The Bowmac concrete panels rest on longitudinal concrete beams at the termination of the blacktop (tarmac), and on rubber wedges inserted into the rail webs to provide a roadway (Figure 1). Beneath the Bowmac panels, the track support structure is sleepers on ballast.

A schematic cross section one of a single track level crossing is shown in Figure 3 . The panels will provide some lateral restraint to the track, while the side ballast will be subjected to some additional vertical dead-load stress and some degree of lateral restraint from the longitudinal concrete beams supporting the Bowmac panels. This is significant, because (as has been demonstrated by, for example, Indraratna et al., 2005 and Stewart et al., 1985), horizontal confinement of the ballast has a marked influence on its response, with increased horizontal stress increasing stiffness and reducing susceptibility to settlement. Thus the track at the crossing is likely to have slightly stiffer support and a reduced rate of settlement with loading cycles than the plain line ballasted track on either side.

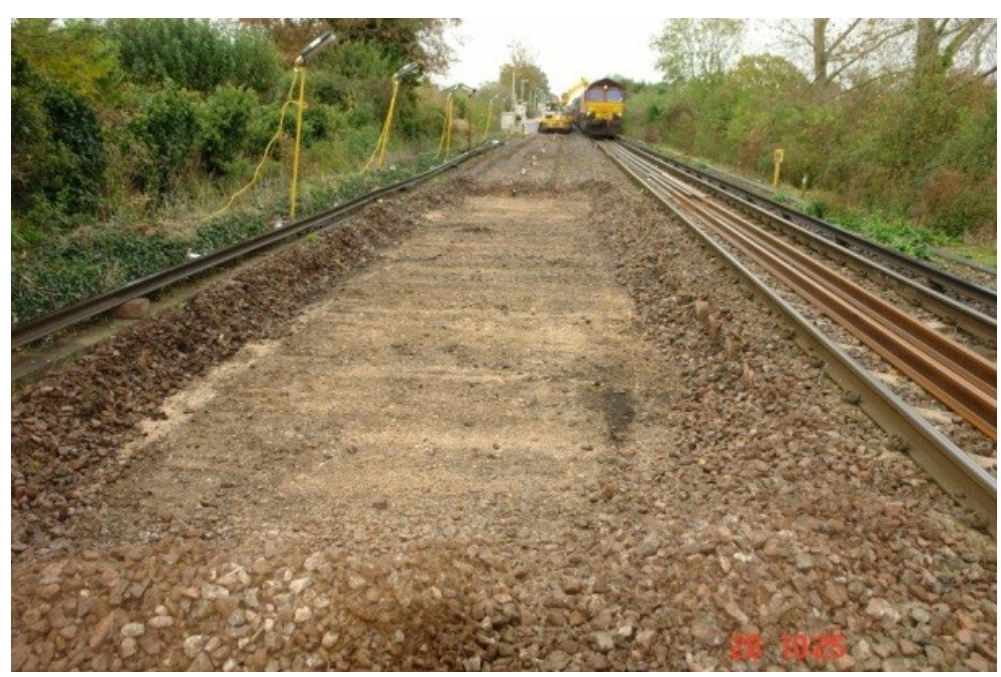

Figure 2: Formation being prepared for track renewal looking towards the nearby station from the level crossing 


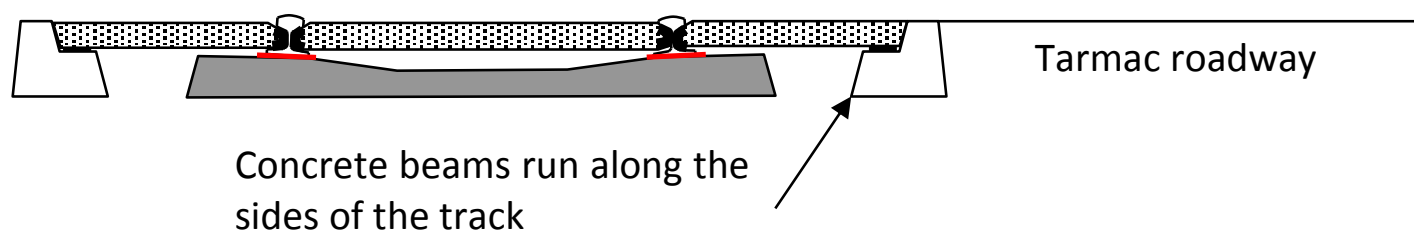

Figure 3: Sketch of the track structure below level crossing

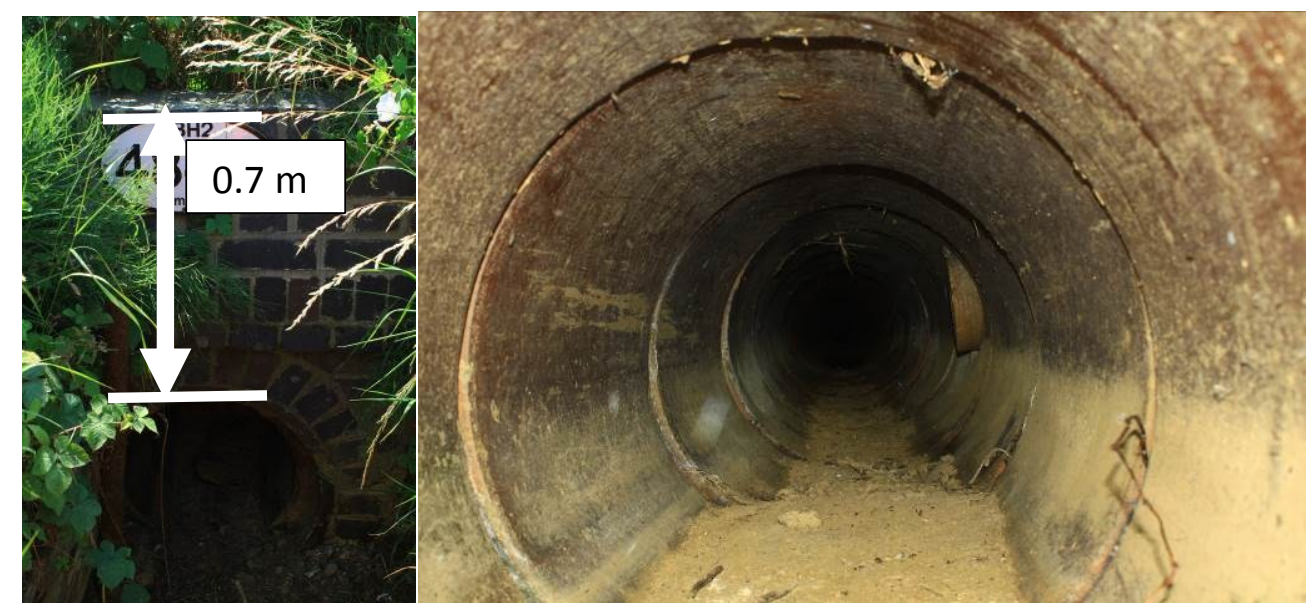

Figure 4: Culvert below the level crossing

\section{Materials and Methods}

\subsection{0n track measurements}

Geophones and digital image correlation (DIC) of video images following the principles described in Bowness et al (2007) were used to determine track movements during train passage along a run of 14 sleepers up to the crossing as shown in Figure 5 . The geophones were placed on 7 alternate sleepers from the termination of the third rail on the approach to the crossing. The geophones are visible in Figure 5 as small cylinders covered in plastic bags with cables connecting them to a Campbell 9000 data logger (Campbell Scientific, 2014) situated beside the track and out of view. The geophones are attached to small metal brackets glued temporarily to the sleepers. 


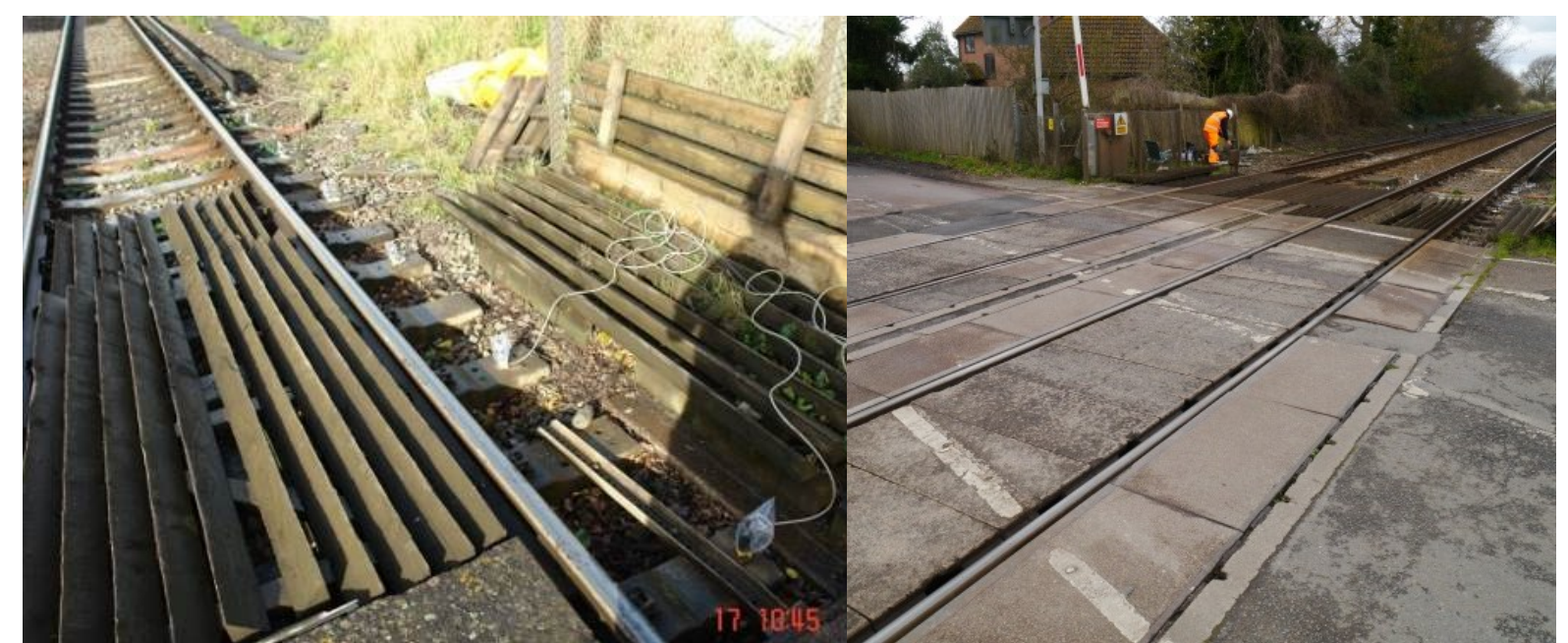

Figure 5: (a) Arrangement of geophones and (b) level crossing viewed from the opposite side of the road from the instrumented section

Figure 6 shows a schematic plan of the instrumented area including various features, dimensions and the numbering of sleepers adopted when presenting the track measurement data. The crossing is skewed (i.e., it is not at $90^{\circ}$ ) to the track with a width generally of $9.6 \mathrm{~m}$ (measured across the road in the direction of the track). Bowmac panels forming the road surface of the crossing are occasionally interspersed with tarmac fill (visible in Figure 5b), perhaps evidencing previous ad hoc repairs to the roadway.

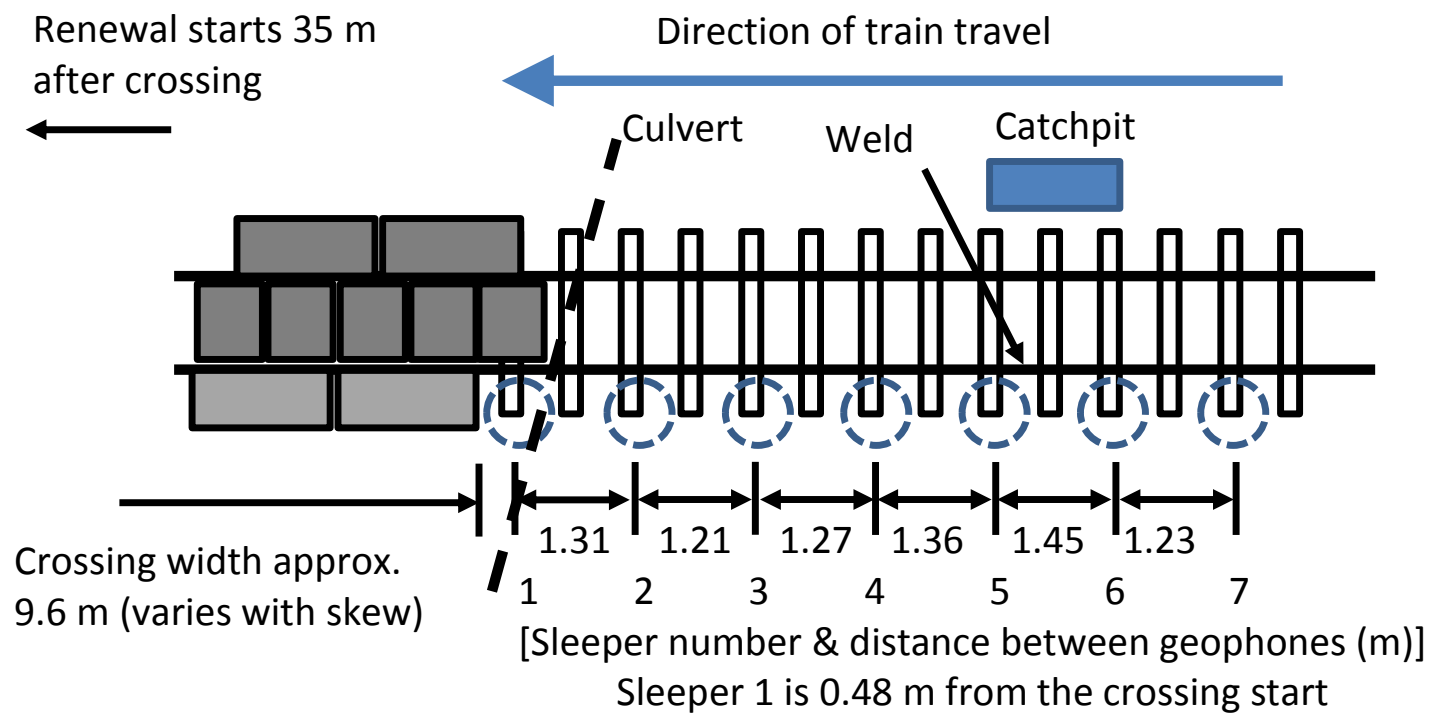

Figure 6: Schematic plan of the area of interest

\subsubsection{Geophones - interpretation}

Techniques using geophones for on-track monitoring of sleeper movements as trains pass have been developed at the University of Southampton over the past ten years or so (e.g. Bowness et al., 2007; Priest et al., 2013; and Coelho et al., 2011). A short summary of the data they provide and their interpretation follows. 
Figure 7 shows a sample of geophone data obtained during passage of a 9 car Pendolino (class 390) train on the West Coast Mainline, UK (WCML). This track is performing well and Figure 7 illustrates typical geophone data in the absence of track faults. The data have been processed to show the displacement against time, and the axles, bogies and cars can be identified in the trace. The displacement data are obtained from the measured raw velocities by integrating and applying signal processing techniques to filter out low frequency data below the threshold of linearity for the geophone used and high frequency data not significant to the major displacements following established mathematical practice (see, for example, Santamarina and Fratta, 2005 or Rao, 1986). Provided the lowest main frequency content measured by the geophones is above a minimum frequency related to the limit of linearity of the geophone used, the geophones are able to measure accurately the peak-to-peak movements of the track. In practice, for the $1 \mathrm{~Hz}$ natural frequency geophones used, the trains generally need to be travelling at more than $30 \mathrm{mph}(45 \mathrm{~km} / \mathrm{h})$. In this example the displacement trace has been calculated following application of a $1 \mathrm{~Hz}$ high-pass and a $30 \mathrm{~Hz}$ low-pass Butterworth filter.

As a result of the (unavoidable) $1 \mathrm{~Hz}$ high pass filter applied, the displacement trace always has a zero mean over any $1 \mathrm{~Hz}$ equivalent ( 1 second) portion of the time trace and it is usual to ignore the first and last axle passes as their relative positions are more significantly affected. In this example, the dashed lines in the plot indicate an estimate of the at-rest sleeper position and the window of best data. Figure 7 shows that the track displaces approximately $0.8 \mathrm{~mm}$; data obtained by the University of Southampton from a variety of sites indicate that displacements between $0.5 \mathrm{~mm}$ and $2 \mathrm{~mm}$ are typical in the UK for ballasted plain line track in serviceable condition. Further details of the first use and development of geophone methods for measuring track movements can be found in Bowness et al., (2007).

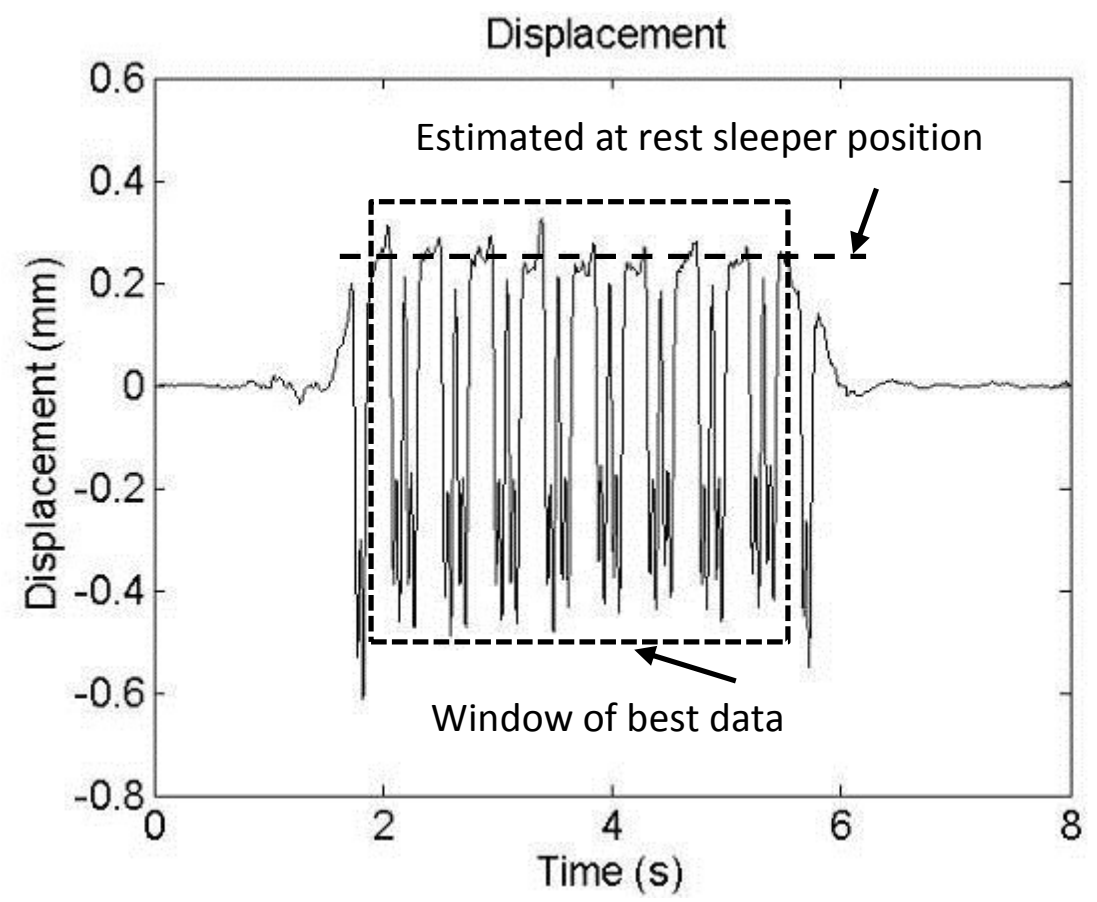

Figure 7: Example geophone data, processed and filtered to give track displacements 


\subsubsection{Image acquisition and analysis}

In addition to geophone measurements of track movements, the University of Southampton has developed a system based on digital image correlation (DIC) to measure the movements of sleepers as trains pass directly (Bowness et al., 2005, and Bowness et al., 2007). Since the details of this system were first published in 2005, the capabilities of digital cameras for the same or less cost have improved dramatically. The current camera has a resolution of 2048 $\times 2048$ pixels and a frame rate of 75 frames per second ( $\mathrm{fps}$ ) at full resolution, and is connected to a laptop PC via a USB 3 interface giving a data transfer rate of up to $320 \mathrm{MB} / \mathrm{s}$. By capturing data from only a reduced portion of the sensor, usually known as the area of interest (AOI), the frame rate can be increased dramatically (e.g. to $315 \mathrm{fps}$ for $640 \times 480$ and up to about $800 \mathrm{fps}$ for smaller areas). Typically, data for a single target can be captured at $500 \mathrm{fps}$.

To aid the analysis and provide a reference for scaling it is usual (although not a requirement of the system) to attach square textured targets to the sleeper ends (Figure 8a). Filming of these targets generates a video file which is then converted to a series of jpeg images for analysis. The analysis is carried out using a variant of the digital image correlation technique described by Bhandari et al. (2012). The technique involves defining measurement (tracking) points and identifying corresponding patterns at these points in the subsequent images using a normalized cross-correlation algorithm. The basic assumptions are that the pattern is approximately constant between successive images and that the local textural information is unique. To allow maximum flexibility a bespoke front end Matlab (Mathworks, 2012) script is used which permits a target (Figure 8a) of known dimensions to be selected. The movement is then determined for a subset of pixels of user defined number in each image in sequence, relative to the initial image.

There are three principal effects that can lead to unwanted noise in the calculated deflections:

- Deflections being small in relation to pixel size

- Groundborne vibration

- Wind due to train passage and/or weather

Controlling these potential sources of error is essential if acceptable data are to be obtained. For the latter two, the difficulty in achieving this tends to increase with train speed. In the worst case (fast trains passing over soft formation), severe ground borne vibrations can mean that optical methods of measuring track movement are not suitable. However, it is usually possible to apply methods to control all three potential sources of errors to acceptable levels as described in the following paragraphs.

Although the normalized cross-correlation algorithm is capable of evaluating the best fit to sub pixel resolution, the accuracy of the fit is influenced by the pixel size. This source of error can be minimised by ensuring that the number of pixels present is appropriate for the expected range of movement (e.g. between 10 and 20 pixels is usually sufficient). To reduce ground-borne vibration (caused by the train passage), the camera is mounted on a tripod whose feet are placed on paving slabs on top of tyre inner tubes inflated to a low pressure (Figure $8 \mathrm{~b}$ ). This isolates the camera from the ground by means of a mass and damper suspension system, thereby removing much of the higher frequency content. However, 
depending on the characteristics of a given site, there may remain some movement at lower frequencies within the typical range of axle and bogie passing frequencies $(1 \mathrm{~Hz}$ to $15 \mathrm{~Hz})$.

Wind influence on the camera position is minimised by placing the camera as close as possible to the ground with the tripod legs set as far apart as possible. There is little wind during train passage, but usually a strong gust after the train has passed. There is also real high frequency content in the sleeper movements due to sources such as rail roughness, which it may be desirable to remove so as to observe the principal sleeper motions. This high frequency content is removed from the data using a post analysis $4^{\text {th }}$ order low pass Butterworth filter to a specified high frequency cut off, typically between $15 \mathrm{~Hz}$ and $30 \mathrm{~Hz}$. Even having applied all these techniques, there will remain some spurious sources of movement in the DIC data that will vary from site to site in accordance with the camera position relative to the track, the specific ground conditions and weather (wind) on the day. Repeated deployment of the system has shown that embankments (particularly over softer formations) are usually more problematic than cuttings for ground-borne vibration, and the best data are obtained when the camera can be situated on a firm support away from the tracks.

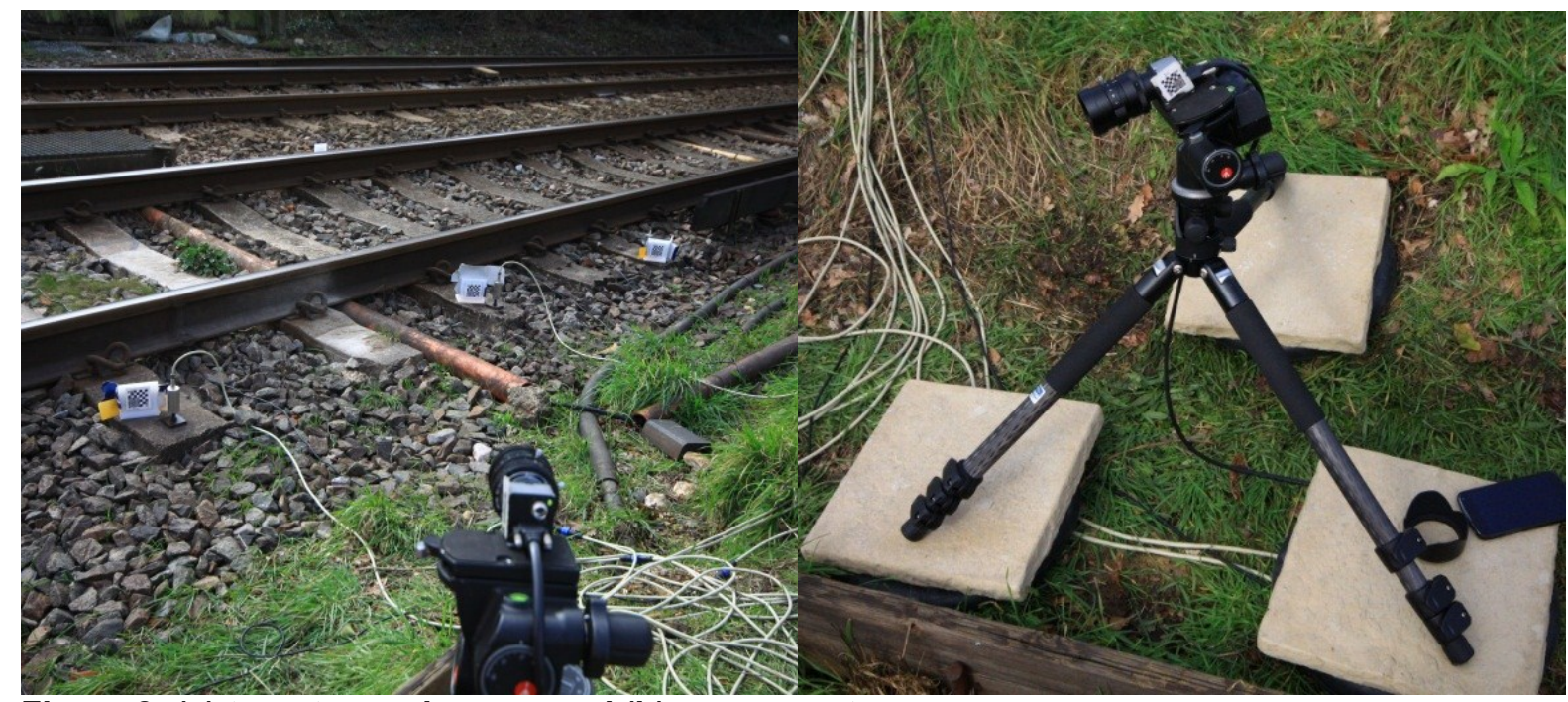

Figure 8: (a) targets on sleepers and (b) camera set up

\subsection{On train measurements}

The track recording car (TRC) operated by Network Rail passes over the site regularly and records the track geometry using accelerometers attached to the axle with instruments located near to both wheels. This data are recorded every $0.2 \mathrm{~m}$ of train movement along the track and the accelerations processed in a similar way to geophone data, except that they are integrated twice to determine displacements. To eliminate errors and average the data over local lengths of track geometry, the data are filtered with a $35 \mathrm{~m}$ and $70 \mathrm{~m}$ maximum wavelength. One result of this is that the data will average to zero within these wavelengths. These data are available and can be interrogated to evaluate changes in track geometry over time. Network Rail maintenance engineers apply established standards for the particular track category (train speed and traffic type) to these data to identify when maintenance interventions are needed. 
In addition to the TRC data, an in-service Class 377 train has been instrumented by the University of Birmingham (UoB) to obtain more frequent, albeit less accurate, track geometry measurements. An inertial measurement system is attached to a bogie to determine the orientation and trajectory of the bogie. From this information the left and right rail vertical geometry can be inferred (Weston et al., 2007). As the bogie is separated from the rails by the primary suspension and its movement driven by both the leading and trailing wheelsets on the bogie, the left and right rail geometry are estimated with some error. Despite this, the results are comparable to the NR TRC at wavelengths longer than $3 \mathrm{~m}$, as will be demonstrated later. Figure 9 shows the class 377 train and the location of the Birmingham instruments.

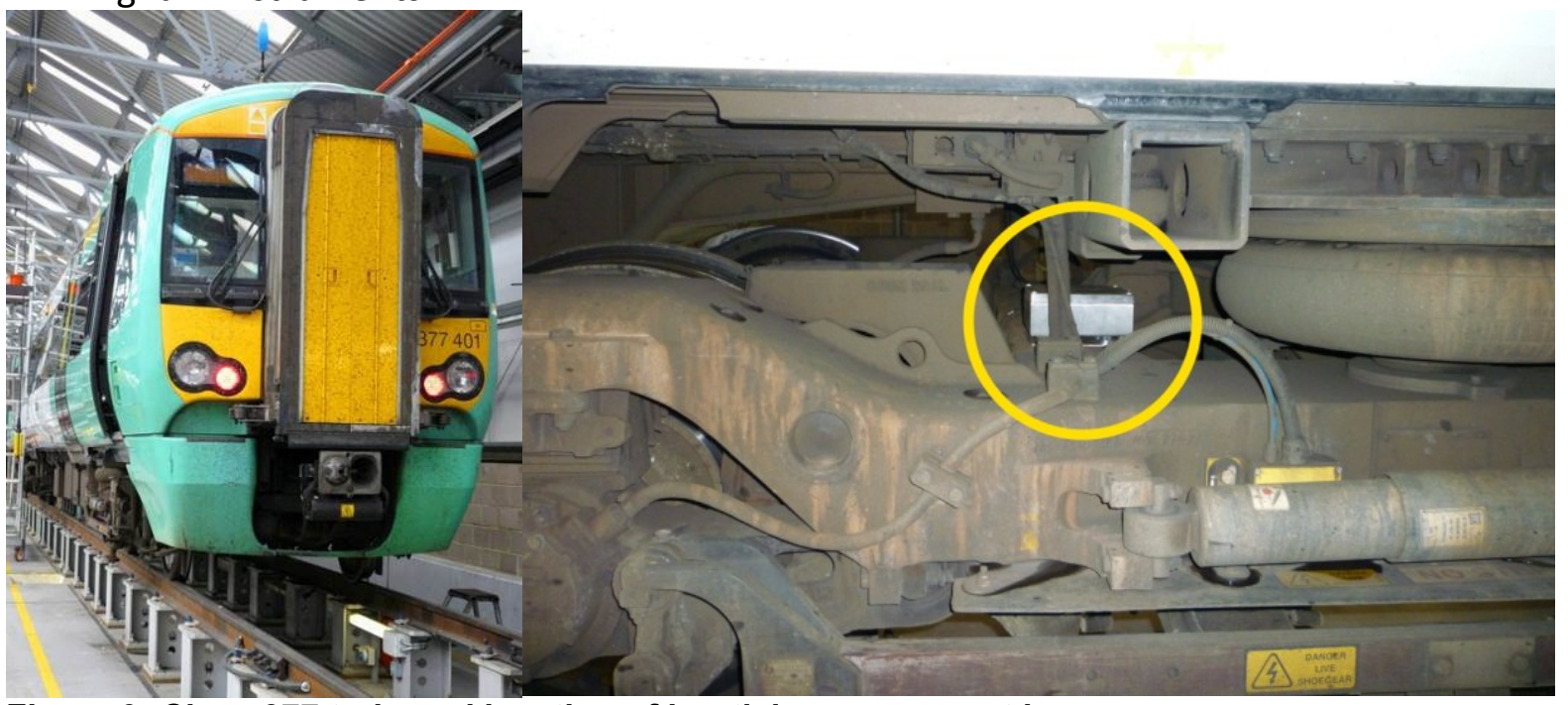

Figure 9: Class 377 train and location of inertial measurement box

\section{Results and discussion}

\subsection{Train data}

In Figure 10, TRC vertical geometry data for the rail nearest the geophone locations are shown for three runs prior to the renewal: between November 2011 and August 2012. In Figure 10, trains are travelling from right to left corresponding to the movement of trains as observed from the near trackside (the side from which the photograph in Figure 1 was taken). The $\mathrm{x}$-axis is shown in relation to the crossing edge on the side being monitored with the crossing being present between approximately 0 and $-9 \mathrm{~m}$. The monitored sleepers 1 to 7 are within approximately 0 to $9 \mathrm{~m}$ on the x-axis. As is usual with this type of data, the relative distance along the track for different runs can vary by some tens of metres. The data can be aligned by adjusting the relative distances, but finding the exact location in relation to track features remains subject to some uncertainty.

The data show little change in vertical alignment over the period, although there is some evidence of a tamping intervention between the November 2011 and July 2012 TRC runs. This had only a minor effect and the track has reached a state of poor quality characterised by a significant range in vertical alignment but more importantly by large changes in vertical geometry over short lengths. However, the vertical alignment is remaining reasonably constant over time so that the rate of track degradation is low and reducing with further cycles of load (Selig and Waters, 1994). 
Network Rail (in common with rail infrastructure operators globally) apply a number of checks to the recorded track geometry data to determine whether the geometry requires maintenance intervention on a scale of urgency in relation to how close the geometry is to comfort or safety related trigger values. Over longer lengths (in the UK, 1/8 mile intervals) the track is usually evaluated by calculating the standard deviation of the vertical geometry with higher standard deviations giving an indicator of the amount of variation in the track. More locally, the geometry data can be converted to measures of specific track faults that may require urgent local attention. The metrics used by Network Rail are given in standard NR/L2/TRK/2101 (Network Rail, 2010). The TRC data show that the study site is a candidate for renewal, although it is worth noting that the geometry both globally (per $1 / 8$ of a mile) and locally (for any specific track geometry fault) is within accepted Network Rail safe limits.

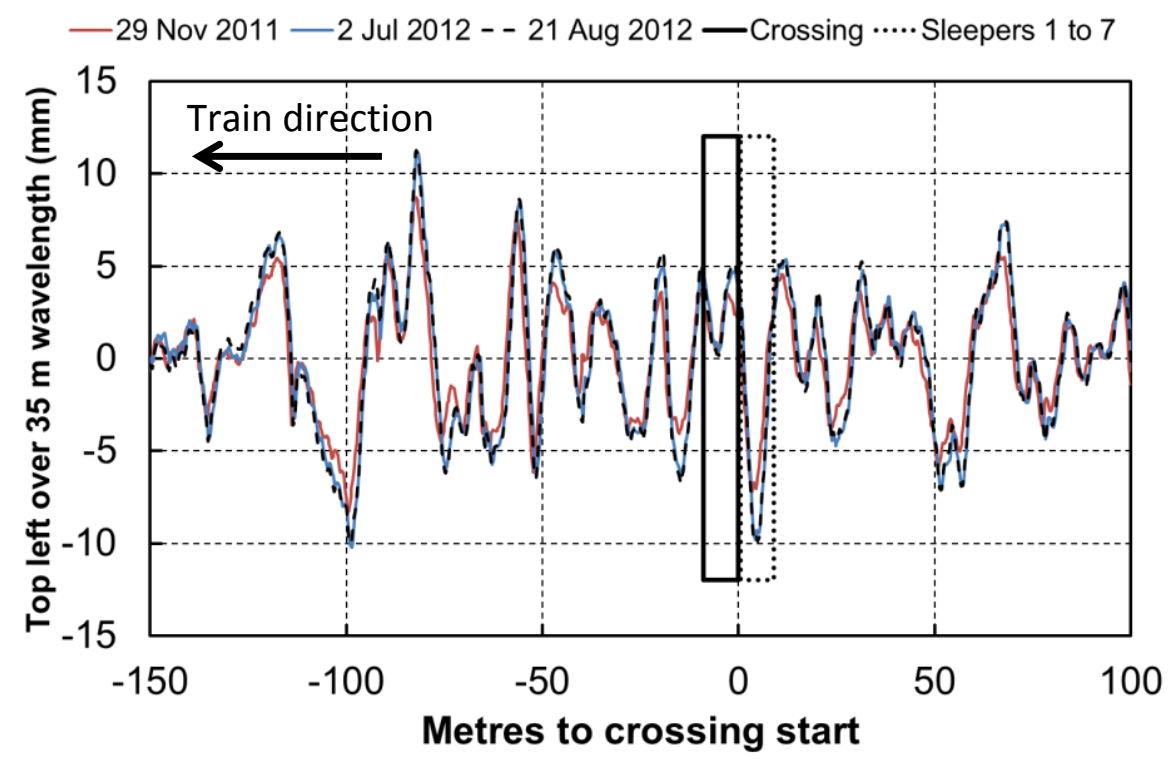

Figure 10: TRC data, top left (vertical alignment of the left rail viewed from the train) prior to renewal

To compare the data from the TRC with those from the UoB instrumented train, a fourth order reverse filter was applied to the averaged top of the TRC data to correct the phase (it is thought the TRC data are only filtered in the forward direction). Figure 11 compares the TRC data from before the renewal with UoB train data from after the renewal. The renewal was observed (measured) to terminate at $35 \mathrm{~m}$ from the opposite side of the level crossing (approximately at $\mathrm{x}=-45 \mathrm{~m}$ in Figures 10 to 12 ); this information enables the uncertainty in the precise location of the level crossing in relation to the train recorded data to be reduced. Between $x=-45 m$ and $x=0 m$ the track geometry is influenced by the adjacent renewal and associated tamping works and the track geometry changes following renewal. At values of $x$ less than $-45 \mathrm{~m}$ there is a dramatic reduction in the variation in track geometry as a result of the renewal. At values of $x$ greater than $0 \mathrm{~m}$ the pre and post renewal data align very closely, with large variations in vertical level both before and after the renewal. 


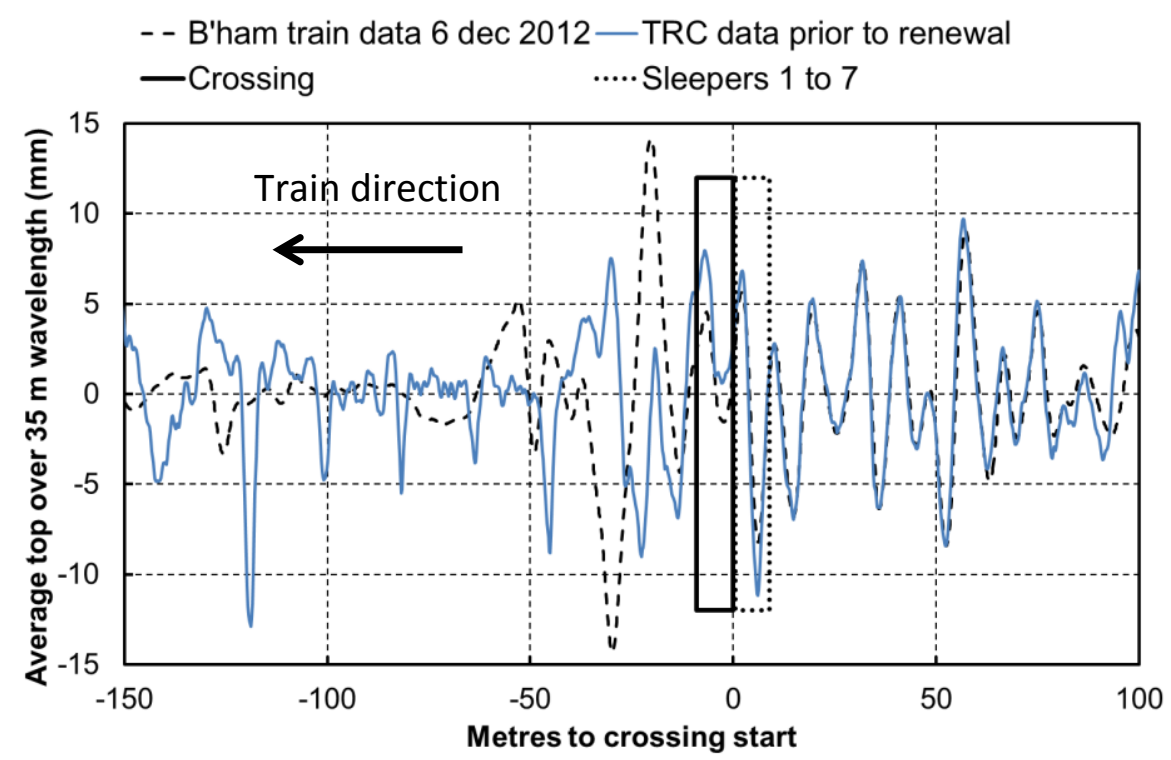

Figure 11: TRC data and UoB instrumented train data, mean top left (vertical alignment)

Figure 12 shows a series of runs of the UoB instrumented class 377 train over the level crossing between December 2012 and June 2013. These data are generally very consistent between runs and little appears to happen at the site until the final run; it is therefore possible to conclude that a maintenance intervention took place between 23 May and 9 June 2013. Further investigation found that tamping took place over the full length of track shown in Figure 12 on 4 June 2013. This had some influence on the data, mainly between $x$ $=0 \mathrm{~m}$ and $\mathrm{x}=-50 \mathrm{~m}$, with relatively minor changes elsewhere.

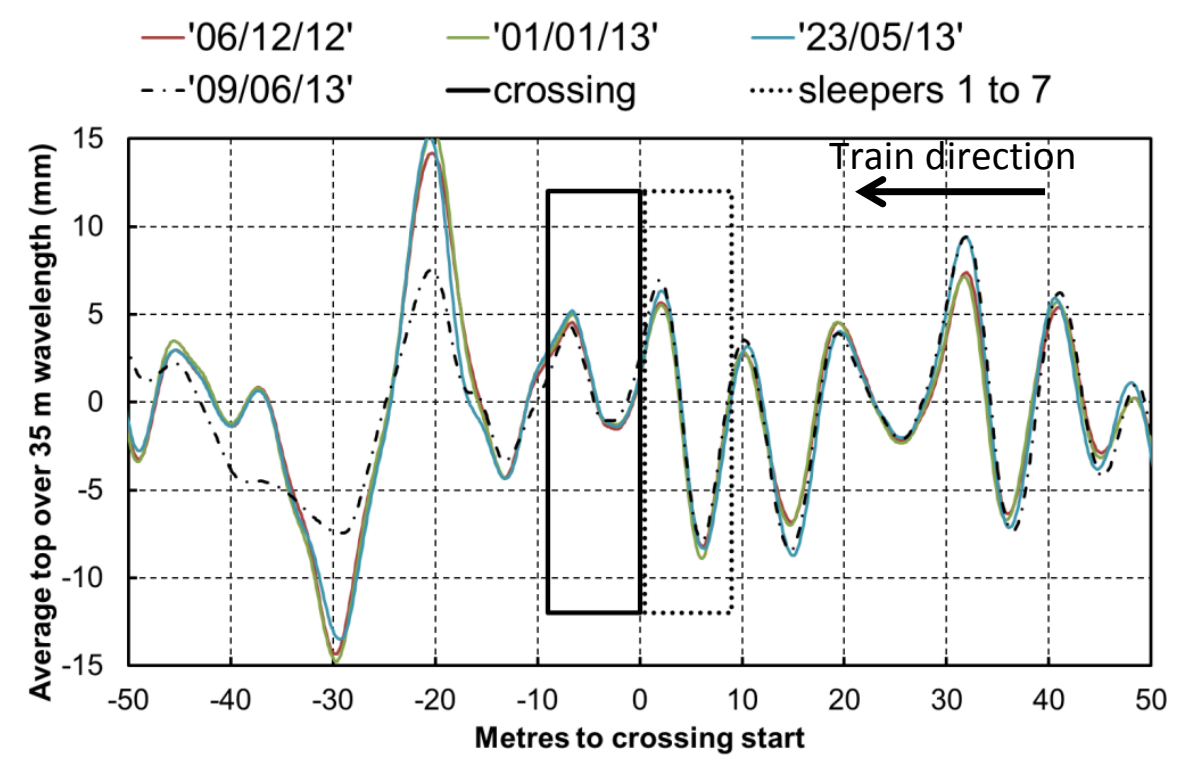

Figure 12: UoB train data, June 2012 to September 2013

\subsection{Trackside data}

Trackside measurements were taken using geophones in October 2012 (prior to the renewal), and using geophones and DIC in July 2013 and March 2014. Vertically-sensing 
geophones were placed on alternate sleepers over a run of 14 sleepers in total (Figure 6) on the cess side of the track. On each visit, data for a number of Class 313 and 377 trains with either 3 car or 4 car configurations were captured. Some of these trains were slowing to stop at the nearby station. The results from the slower trains were discarded as they were travelling too slowly to provide reliable geophone data (although the DIC data were fine). The line speed was $70 \mathrm{mph}$; the faster, non-stopping, trains generally were travelling at 60 $\mathrm{mph}$ to $70 \mathrm{mph}$. On the weekdays when measurements were taken there were typically four trains per hour. Both classes of train showed similar behaviour and a characteristic data set from each of the three visits for a class 377 travelling at approximately $65 \mathrm{mph}$ is presented here.

To provide a context within which to intrepret the site data, we first consider the expected behaviour using a beam on elastic foundation analogy for which the mathematics is well established (e.g. Timoshenko, 1927; Raymond, 1985), and apply the principle of superposition to determine the track deflection using the following data:

- sleeper spacing $=0.65 \mathrm{~m}$;

- support stiffness $=15 \mathrm{kN} / \mathrm{mm}$ per sleeper end (or $\sim 23 \mathrm{kN} / \mathrm{mm}$ per $\mathrm{m}$ of track), chosen to give a deflection similar to that measured at some sleepers.

- axle and carriage dimensions for a class 377 ; axle spacing $=2.600 \mathrm{~m}$, bogie spacing = $11.573 \mathrm{~m}$, car spacing $=19.980 \mathrm{~m}$ )

- axle load = 12 tonnes (corresponding to the axle weight for motorised cars of a class 377)

- $56 \mathrm{~kg} / \mathrm{m}$ rail with second moment of cross sectional area I $=23250000 \mathrm{~mm}^{4}$ and Young's modulus $\mathrm{E}=209000 \mathrm{~N} / \mathrm{mm}^{2}$ )

- train speed $=65 \mathrm{mph}(\sim 29 \mathrm{~m} / \mathrm{s})$.

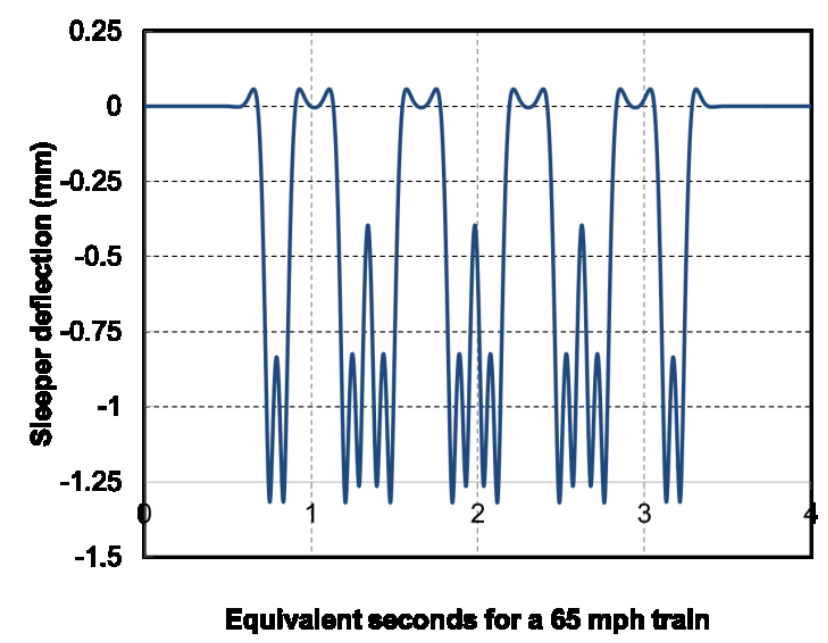

Figure 13: Theoretical track deflection for 4 car class 377 train travelling at $65 \mathrm{mph}$

Figure 13 shows interaction between adjacent axles and bogies with the track only returning to its initial position between cars, where there is also some uplift due to the bending stiffness of the rails.

For comparison, the track deflections measured at sleeper 4 for a 4 car class 377 during the March 2014 visit are shown in Figure 14. This highlights some key features of the 
geophone/DIC data and characteristics of the site in comparison with the theory which can be summarised as:

- The track at this sleeper has a lower support stiffness than used in the the example calculation, as shown by the larger movement and the trace fluctuating more. In particular there is a repeating feature (circled), which is thought to be caused by the impact load at a previous hanging sleeper. This is discussed later.

- Due to the processing techniques applied it is necessary to ignore the first and last bogies in the geophone data. Also, the geophone data are normally averaged about zero but in Figure 14 the trace has been migrated so that zero is an estimate of the at rest sleeper position.

- The DIC data and geophone data are in close agreement for the middle 6 bogies

- The DIC data includes some low frequency groundborne or wind generated vibration, which can be seen on its own after the train has passed (oscillations between 4 and 5 seconds).

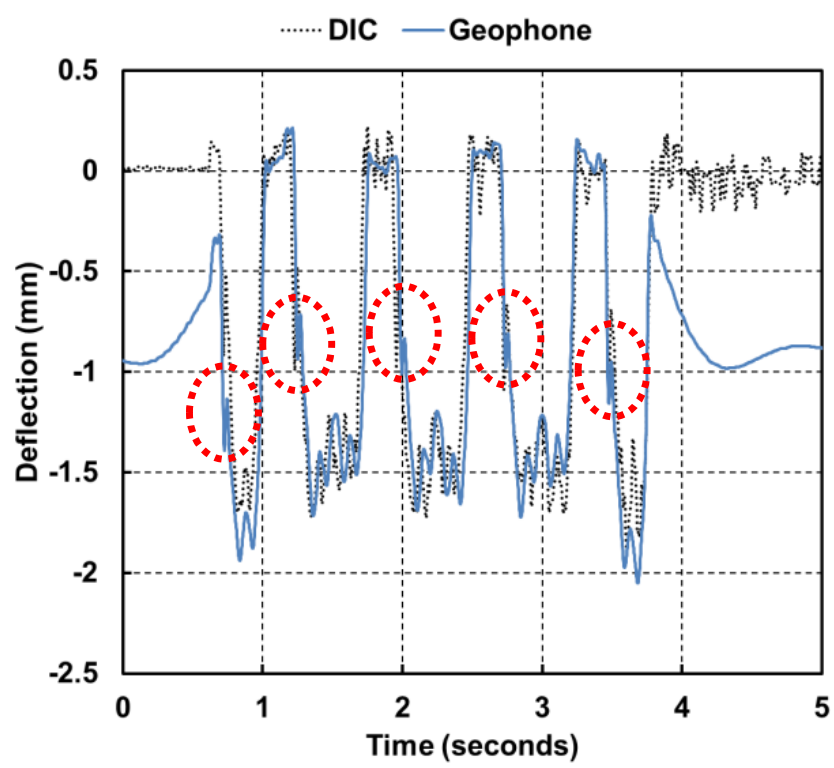

Figure 14: Track measurements at sleeper 4 for a class 377 train travelling at approximately 65 $\mathrm{mph}(29 \mathrm{~m} / \mathrm{s})$

Figure 15 shows data from 3 train passes, one from each visit, for all of the instrumented sleepers ( 7 to 1 , in the order traversed by the train). The trains were travelling at approximately $65 \mathrm{mph}(\sim 29 \mathrm{~m} / \mathrm{s})$ and the data have been shifted fractionally so that each trace overlays. The vertical scales differ in between graphs, but note the large changes in movement from sleeper to sleeper.

Examination of the geophone measurements for sleeper 5 from all the visits and for sleeper 6 for the first visit revealed that on these occasions the geophones were reaching their maximum speed of movement and sleeper movements were probably in excess of $5 \mathrm{~mm}$. DIC measurements for sleeper 5 were taken on the latter two visits and confimed that the movement range was nearly $6 \mathrm{~mm}$. The data for sleeper 5 match the shape of the data expected from theory; however, the data from all of the other sleepers have features that 
should not be there as indicated by the dotted circles in Figure 14. It is thought that a large impact is occuring at sleeper 5 , which is causing the unusual movements that are not in phase with the axle passage at the other sleepers.
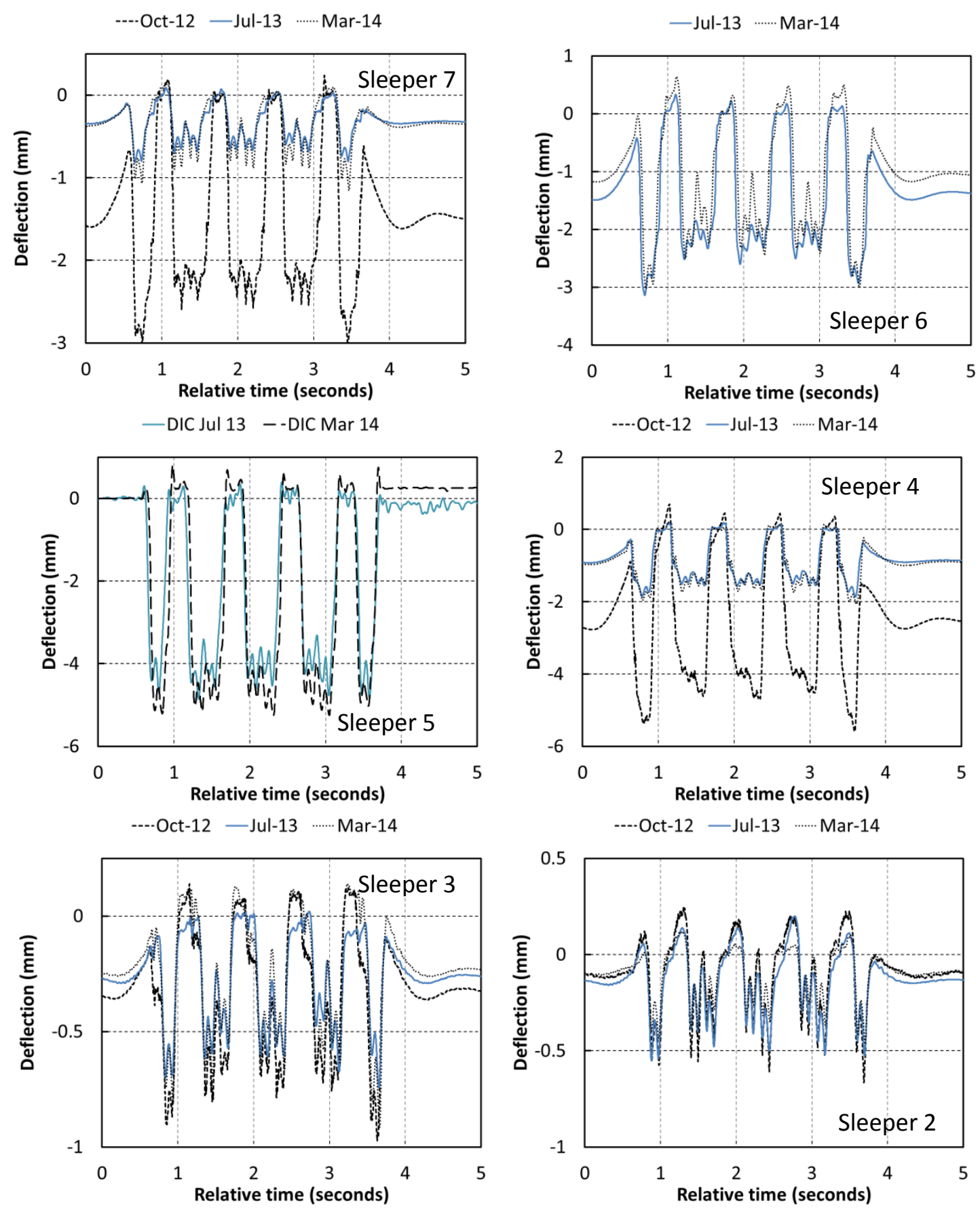


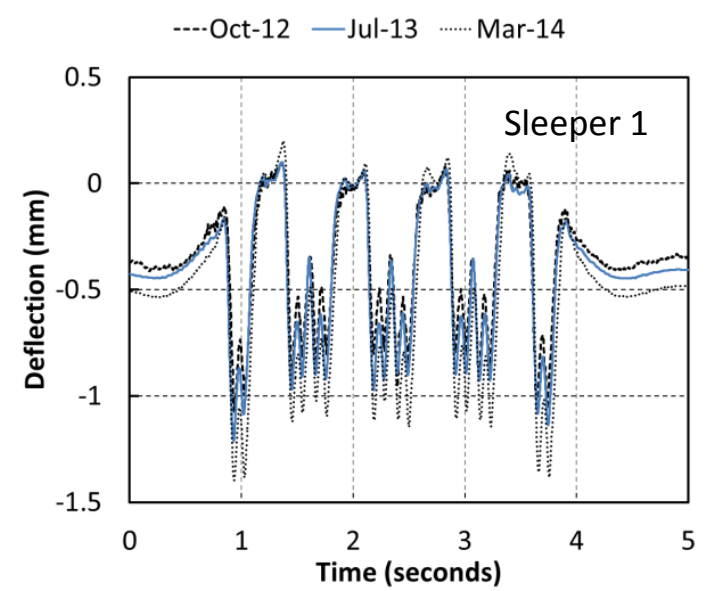

Figure 15: Geophone data from the three visits for sleepers 7, 6, 4, 3, 2, 1 and DIC data from the two more recent visits for sleeper 5 . The geophone data are filtered between 1 and $30 \mathrm{~Hz}$ and the DIC data have a low pass filter with a high cut off frequency of $18 \mathrm{~Hz}$. Geophones for sleeper 5 were omitted because their movement was too fast for the sensors.

Figure 16 summarises the sleeper movements for axle 7 as a bar graph. Both Figures 15 and 16 show that there is some improvement in performance of this section of track following the tamping (or Kango packing) of 4 June 2013 as evidenced by the reductions in some of the geophone movements. However, the track performs very poorly on all visits in terms of large variations in movement between nearby sleepers and the generally low support stiffness. In particular, sleepers 5 and 6 show large movements, indicating that they are almost certainly hanging (voided). Sleepers 1 and 2, nearest the crossing and possibly over the culvert, are performing the best in the sense that their movement is consistent between visits and generally small $(<1.5 \mathrm{~mm})$. Sleepers 7 and 4 show the greatest improvement in terms of a reduction in the movement as a result of the tamping intervention of 4 June 2013.

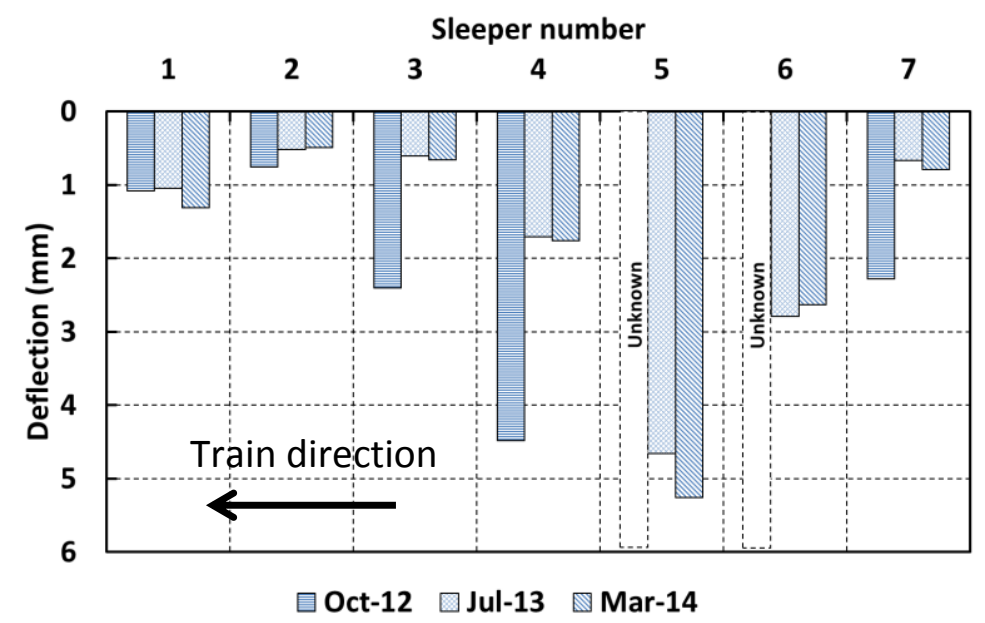

Figure 16: Sleeper deflections for axle 7 of a class 377 train travelling at approximately $65 \mathrm{mph}$ $(\sim 29 \mathrm{~m} / \mathrm{s})$; data from all visits for all sleepers

Figure 16 shows that prior to the tamping of 4 June 2013, the largest sleeper movements were centred around sleepers 5 and 6 (which were offscale for geophone measurements) and sleeper 4 . These movements are consistent with a lack of support due to sub-sleeper 
voids (hanging sleepers), possibly as a result of the change in support conditions over the transition onto the crossing and the local constraints imposed on maintenance operations.

The sleepers nearest to the crossing, particularly 1 and 2, appear to benefit from greater support stiffness; this could in part be due to the influence of the crossing with the bending stiffness of the rails serving to transfer the increased stiffness slightly beyond the boundary of the crossing. There may also be some benefit in terms of increased support stiffness below sleepers 1 and 2 of the drainage culvert passing beneath the track (see figure 6 for an estimate of the culvert centre line). Starting from sleeper 3 an increased deflection bowl centred on sleeper 5 can be traced all the way to sleeper 7; this indicates a region of voided sleepers that could have been caused by increased dynamic loads from the change in support conditions onto the crossing similar to that seen at transitions onto bridges (e.g. Paixao et al., 2013).

The mechanised tamping that took place in June 2013 is likely to have been curtailed up to $20 \mathrm{~m}$ back from the crossing, with hand-held pneumatic (Kango-type) hammers used to pack the ballast beneath sleepers 1 to 7 . The effectiveness of this was least where the sleeper movements were greatest, probably as a result of the maintenance constraints imposed by the nearby crossing but also the increased accumulated damage to the track bed. The presence of the crossing will have prevented a design tamping overlift from being applied near to the crossing, so that the maintenance will have been less effective with the track subsequently more likely to degrade at a faster rate than the track further away from the crossing. The ballast itself is likely to have suffered more compaction, attrition and breakage below sleepers 4-6 as a result of the impact loading associated with voiding. These effects mean that the maintenance is likely to have been least effective beneath the sleepers initially behaving the poorest - this is borne out by Figure 16, which shows that the sleepers clearly hanging prior to the maintenance $(4,5$ and 6$)$ benefitted least from the maintenance, with sleepers 5 and 6 being clearly still hanging after the maintenance intervention of 4 June 2013.

\subsection{Comparison of train and track data}

The geophone and DIC measurements provide data on track deflections as trains pass. These deflections may have components due to both a hanging sleeper and the trackbed. If the load is known, the deflection data can be used to estimate the track stiffness on the basis of a beam on an elastic foundation analysis (see e.g. Timoshenko, 1927; Raymond, 1985; Esveld, 2001; and Priest et al., 2013). The foundation modulus can then be converted to a spring stiffness per sleeper where the magnitude of the deflection is proportional to a lumped average support stiffness.

Train mounted track geometry recording systems like those described in this paper where the instrumentation is mounted near the bogies/wheelsets provide a measure of the loaded track geometry. If it is assumed that the track is approximately level when unloaded, the loaded track geometry and track deflections would be expected to correlate approximately, particularly at severe track faults such as hanging sleepers. Usually, however, it is very 
difficult to align train measurement data with specific sleepers. In the case of the level crossing studied, the renewal on the "downstream" side has provided a way to increase confidence in the alignment of the two data sets (on-train and trackside).

Figure 17 compares the TRC data prior to the renewal in October 2012 and two UoB instrumented class 377 train runs from before and after the tamping of June 2013 with the magnitudes of sleeper movement from the geophone and DIC measurements. This comparison shows that the track measurements of deflection do indeed lie around a relative dip in the train recorded track geometry, which corresponds to the position of the worst hanging sleepers.

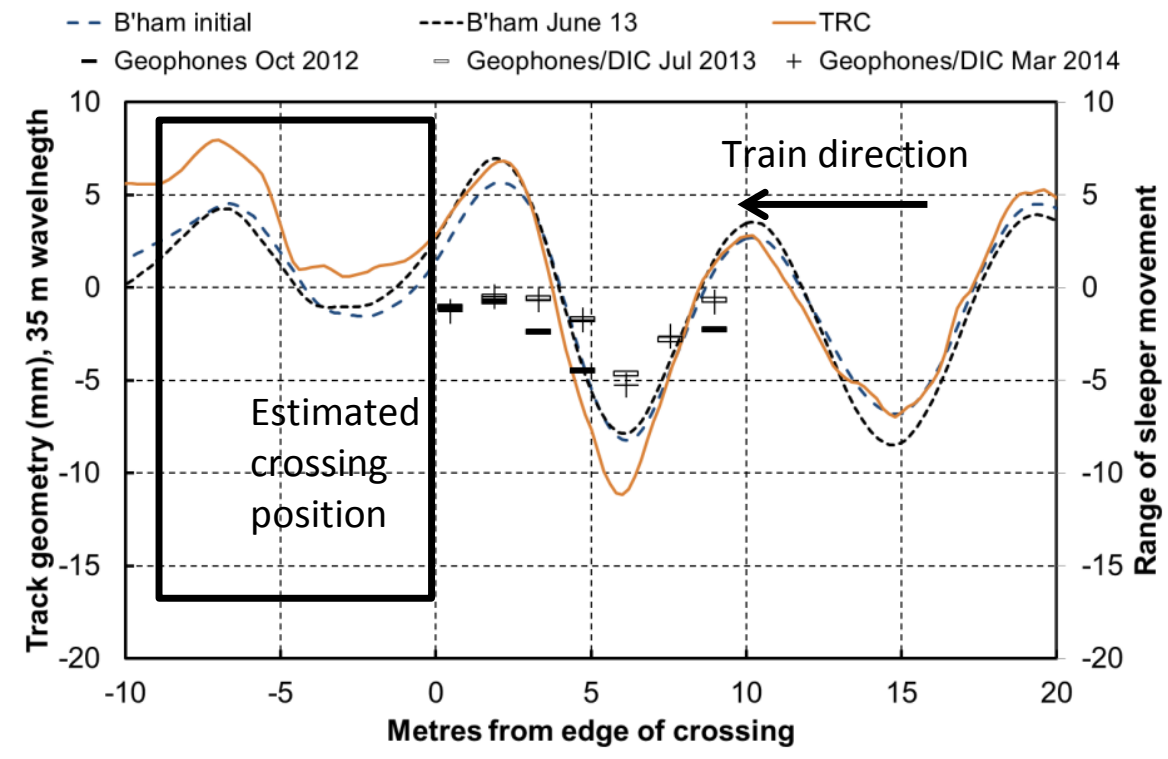

Figure 17: Comparison of TRC data prior to renewal, UoB train data and geophone data before and after follow up tamping on 4 June 2013.

It is also worth noting that the data from individual sleepers obtained using DIC and geophone measurements, together with the additional effort made to align the deflected vertical profile determined from on-train measurements, provide information greatly in excess of that normally available to practising maintenance engineers. Also, at this site there was no visual evidence that sleepers 5 and 6 were voided. Had there been such evidence, it is likely that they would have been identified as requiring individual maintenance. The results of this case study are currently being used in collaboration with Network Rail to inform the development of improved track diagnostics and maintenance strategies.

\section{Conclusions}

Trackside measurements using geophones and digital image correlation (DIC) have shown that on-train measurements are able to identify changes in track support stiffness that occur as a result of tamping and renewal. Data from a bogie mounted inertial sensor were generally comparable with those obtained from a TRC. Normally the level of detailed analysis needed to align data recorded from trains and trackside is not possible, but in this case the nearby renewal provided a reference point that enabled train and track measurements to be aligned locally to give consistent data. 
The measurements have shown that tamping was not particularly effective in removing voided sleepers on the approach/transition to a traditional level road crossing, perhaps because lifting and tamping by machine is not possible right up to the crossing itself which remains as a fixed point in terms of its vertical position. Hanging sleepers evident before tamping remained or re-appeared very soon afterwards. In contrast at locations further away from the crossing, tamping improved both the vertical alignment of the track and the consistency of the sub-base stiffness.

Maintenance interventions or local remediation measures aimed at preventing hanging sleepers from occurring would ideally be implemented at this site. There is currently no specific routine intervention that could target individual sleepers susceptible to voiding, although one possible approach, based on self-levelling sleepers that react to a loss of support due to voiding by automatically increasing their depth, is currently being trialled in Japan (Muramoto et al., 2013).

\section{Acknowledgements}

The authors are grateful for the financial support of the Engineering and Physical Sciences Research Council (EPSRC) through the Programme grant TRACK21 (EP/H044949/1), and for the financial support of Network rail through Strategic University Research Partnerships in Future Infrastructure Systems (Southampton) and Data Integration and Management (Birmingham). This work would also not have been possible without the kind assistance and advice given by a number of current and past Network Rail employees including Daren Smith, Robert Holbrow, Mike Edwards, Andrew Cornish and Niall Fagan.

\section{References}

Aingaran, S. 2014. Experimental investigation of static and cyclic behaviour of scaled railway ballast and the effect of stress reversal. Ph.D. dissertation, Faculty of Engineering and the Environment, Univ. of Southampton, Southampton, U.K.

Banimahd, M., Woodward, P. K., Kennedy, J. \& Medero, G. M. 2012. Behaviour of train-track interaction in stiffness transitions. Proceedings of the ICE - Transport [Online], 165. Available: http://www.icevirtuallibrary.com/content/article/10.1680/tran.10.00030.

Bhandari, A., Powrie, W. \& Harkness, R. 2012. A Digital Image-Based Deformation Measurement System for Triaxial Tests. ASTM geotechnical testing journal, 35, 209226.

Bowness, D., Lock, A., Powrie, W., Priest, J. \& Richards, D. 2007. Monitoring the dynamic displacements of railway track. Proceedings of the Institution of Mechanical Engineers, Part F: Journal of Rail and Rapid Transit, 221, 13-22.

Bowness, D., Lock, A. C., Richards, D. J. \& Powrie, W. 2005. Innovative remote video monitoring of railway track displacements. In Proc: Applied Mechanics and Materials, Southampton, United Kingdom. 3-4, 417, Trans Tech Publications, ClausthalZellerfeld, D-38670, Germany

Campbell Scientific. 2014. http://www.campbellsci.com/cr9000x. [Accessed 29 April 2014]. 
Coelho, B., Hölscher, P., Priest, J., Powrie, W. \& Barends, F. 2011. An assessment of transition zone performance. Proceedings of the IMechE Part F, Journal of Rail and Rapid Transit, 225, 129.

Esveld, C. 2001. Modern Railway Track, Zaltbommel, MRT Productions.

Indraratna, B., Lackenby, J. \& Christie, D. 2005. Effect of Confining Pressure on The Degradation of Ballast Under Cyclic Loading. Geotechnique, 55, 325-328.

Fiberweb Geosynthetics Ltd. 2014. http://www.terram.com/marketsector/railways/?aaopen=ballast-over-weak-subgrades. [Accessed 29 April 2014 2014].

Li, D. \& Davis, D. 2005. Transition of Railroad Bridge Approaches. Journal of Geotechnical and Geoenvironmental Engineering, 131, 1392-1398.

Mathworks. 2012. Matlab [Online]. Available: http://www.mathworks.co.uk/products/matlab/ [Accessed May 2012].

Muramoto, K., Nakamura, T. \& Sakurai, T. 2013. A track irregularity prevention method for the transition zone between different track structures using Automatic Irregularitycorrecting Sleeper. In Proc: World Congress on Railway Research, Sydney, Australia.

Network Rail 2012. NR/L3/TRK/4041 Maintaining Track Assets at Level Crossings, June 2012, Network Rail, Kings Place, 90 York Way, London, N1 9AG.

Network Rail. 2010. Network Rail Level 2, NR/L2/TRK/2101, Design and construction of track, Network Rail, Kings Place, 90 York Way, London, N1 9AG.

Network-Rail 2009. NR/TRK/8100, Railway Ballast and Stoneblower aggregate, Issue 4. June 2009, Network Rail, Kings Place, 90 York Way, London, N1 9AG.

Paixao, A., Fortunato, E. \& Calcada, R. 2013. Design and construction of backfills for railway transition zones. Journal of Rail and Rapid Transit, Online 28 August.

Priest, J., Powrie, W., Le Pen, L., Mak, P. \& Burstow, M. 2013. The effect of enhanced curving forces on the behaviour of canted ballasted track. Journal of Rail and Rapid Transit, 27.

Rao, S. S. 1986. Mechanical vibrations. Addison-Wesley, Reading, Massachusetts.

Raymond, G. P. 1985. Analysis of Track Support and Determination of Track Modulus. Transportation Research Record, 1022, 80-90.

Santamarina, J. C. \& Fratta, D. 2005. Discrete Signals and Inverse Problems: An Introduction for Engineers and Scientists, John Wiley and Sons Ltd, Chichester, UK.

Selig, E. T. \& Waters, J. M. 1994. Track Geotechnology and Substructure Management, London, Telford.

Stewart, H. E., Selig, E. T. \& Norman-Gregory, G. M. 1985. Failure Criteria and Lateral Stresses in Track Foundations. Transportation Research Record, 1022, 59-64.

Timoshenko, S. 1927. Proceedings Second International Congress of Applied Mechanics: Methods of Analysis of Statical and Dynamical Stresses in Rails. In Proc: Zurich. 407418,

Track 21. 2014. Track 21 - Railway Track for the 21st Century [Online]. Available: http://www.track21.org.uk/

Tutumluer, E., Stark, T. D., Mishra, D. \& Hyslip, J. P. 2012. Investigation and Mitigation of Differential Movement at Railway Transitions for US High Speed Passenger Rail And Joint Passenger/Freight Corridors. Proceedings of the 2012 Joint Rail Conference, JRC2012. April 17-19, 2012, Philadelphia, Pennsylvania, USA. 
Weston, P., Ling, C., Roberts, C., Goodman, C., Li, P. \& Goodall, R. 2007. Monitoring vertical track irregularity from in-service railway vehicles,. Proceedings of the IMechE: Part $F$ - Journal of Rail and Rapid Transit, 221(1), 75-88. 